\title{
Ergonomia física: as exigências presentes na atuação de modelista do vestuário
}

Physical ergonomics: current requirements for the fashion designer

Sabrina Helena Planca

Pós-graduada em Docência na Educação Profissional e Tecnológica - Senai CETIQT sabrinahplanca@gmail.com

\section{Eugenio Andrés Díaz Merino}

Doutorado em Engenharia de Produção pela Universidade Federal de Santa Catarina, eugenio.merino@ufsc.br

\section{Giselle Schmidt Alves Díaz Merino}

Doutora em Engenharia de Produção - UFSC gisellemerino@gmail.com 


\title{
Ergonomia física: as exigências presentes na atuação de modelista do vestuário
}

Physical ergonomics: current requirements for the fashion designer

\author{
Sabrina Helena Planca, Eugenio Andrés Díaz Merino e Giselle Schmidt Alves \\ Díaz Merino
}

\section{Resumo}

As indústrias de confecção de vestuário representam um setor importante da economia no Brasil. Em 2012, o país foi classificado como a quarta maior potência na atividade industrial de confecção de vestuário e acessórios do mundo. Uma das atividades que faz parte do processo produtivo de confecção é a de modelagem. Neste caso, foi analisada a atividade realizada em um escritório de modelagem com o objetivo de identificar as exigências físicas associadas a atividade, como forma de gerar um diagnóstico e propor medidas de melhoria. Para esta finalidade o estudo foi dividido em duas etapas, sendo uma de cunho teórico que buscou levantar uma base teórica sobre o assunto e outra de cunho aplicado, caracterizando-se como estudo de caso em um escritório de modelagem, localizado na cidade de Gaspar/SC, se utilizando de observações, visitas in loco, entrevistas e a aplicação do Questionário Nórdico.

Palavras- chave: ergonomia, modelista, confecção de vestuário.

\begin{abstract}
Apparel industries represent an important sector of the economy in Brazil. In 2012, the country was classified as the fourth largest trader of clothes and accessories manufacture in the world. Modeling, one of the activities that is part of the productive process of manufacture. In this study, we analyzed the activity carried out by a modeling bureau with the aim of identifying the physical requirements associated with the activity, as a way of generating a diagnosis and proposing improvement measures. To reach such a goal, the study was divided into a theoretical stage and an applied stage. The former sought to build a theoretical basis about the topic. The latter consisted of a case study conducted in a modeling bureau located in the city of Gaspar, Santa Catarina state. The study design involved observations, site visits, interviews and the application of the Nordic Questionnaire.
\end{abstract}

Keywords: ergonomics, designer, clothes making sector. 


\section{INTRODUÇÃO}

A ergonomia estuda o trabalho e sua relação com o sistema-homem-máquina, buscando modificá-la, com o objetivo de proporcionar conforto, segurança e eficiência do trabalhador (IIDA, 2005). As aplicações práticas da ergonomia surgiram como consequência da industrialização, a qual teve seu início na Revolução Industrial, no século XVIII.

No contexto industrial brasileiro, as indústrias de confecção de vestuário representam um setor importante da economia. Conforme a Associação Brasileira da Indústria Têxtil e de Confecção - ABIT (OMC apud ABIT, 2015), em 2012, o país foi classificado como a quarta maior potência na atividade industrial de confecção de vestuário e acessórios do mundo. O estado de Santa Catarina se destaca no setor, principalmente, pela Região do Vale do Itajaí, sendo descrita como um dos polos têxteis e confeccionistas mais avançados do país e por sua participação significativa na produção e empregos neste setor.

Assim como outros processos produtivos, o trabalho desempenhado em muitas das funções de uma indústria de confecção é bastante desgastante, principalmente em função de seu ritmo acelerado. No processo produtivo de confecção do vestuário, uma das atividades realizadas é a de modelagem, desempenhada pelo profissional chamado de modelista, o qual é responsável por desenvolver os moldes dos modelos constantes da coleção, viabilizando a produção em grande escala. A modelagem pode ser realizada internamente ou, de forma externa em escritórios (bureaux) de modelagem. No caso deste estudo, foi analisada a atividade realizada em um bureau de modelagem.

Entre os domínios de especialização da ergonomia, está a ergonomia física, a qual trata das características da anatomia humana - antropometria, fisiologia, biomecânica - e sua relação com as atividades físicas, bem como, o estudo da postura durante o trabalho - manuseio de materiais, esforços repetitivos, entre outros (ASSOCIAÇÃO BRASILEIRA DE ERGONOMIA, 2015). Além dos aspectos físicos, a ergonomia também engloba os aspectos cognitivos e organizacionais. Porém, para este estudo o foco são as exigências físicas, já que, o pressuposto é que as mesmas tenham maior influência no desempenho das funções na atividade de modelista. Isto não exclui a importância dos demais aspectos, constituindo assim, um campo a ser explorado em futuras pesquisas. 
As atividades de modelagem, geralmente, são informatizadas. Portanto, a postura sentada é predominante, assim como, a repetição de movimentos. A precisão das medidas e dos traçados utilizados para a modelagem também contribuem para aumentar as exigências visuais e de atenção. As posturas incorretas condicionadas pelo ambiente, em especial pelo mobiliário e equipamentos informatizados, associadas às exigências de produção evidenciam ainda mais, os riscos físicos que podem trazer prejuízos à saúde do modelista.

A atividade de modelista, assim como a de costureira, caracteriza-se pela manutenção de postura estática por períodos prolongados e alto grau de concentração e detalhamento. Estes aspectos podem comprometer a saúde do trabalhador, sendo que, as queixas normalmente estão relacionadas às dores corporais, ao cansaço físico e mental (SENA et al., 2008 apud MAZINI FILHO et al., 2014). Assim, identificar os riscos físicos resultantes da atividade faz-se necessário para reduzir suas consequências e evitar que maiores prejuízos possam ser causados aos trabalhadores e à empresa (ORSELLI, 2010 apud MAZINI FILHO et al., 2014).

Portanto, justifica-se esta pesquisa por ampliar o escopo da utilização da ergonomia, aplicando-a em estudos voltados à atividade de modelista do vestuário, contribuindo com a construção do conhecimento e incentivando mais pesquisas voltadas ao setor e à ocupação, prevenindo ou corrigindo aspectos do trabalho que possam causar danos à saúde.

Esta pesquisa tem como objetivo identificar as exigências físicas associadas a atividade de modelista do vestuário realizadas em um bureau de modelagem localizado na cidade de Gaspar/SC, como forma de gerar um diagnóstico e propor medidas de melhoria.

\section{PROCEDIMENTOS METODOLÓGICOS}

\subsection{Caracterização geral}

Este estudo caracteriza-se como uma pesquisa de natureza aplicada com o objetivo gerar conhecimentos voltados para a solução de problemas específicos. A forma de abordagem do problema é qualitativa, considerando que há uma relação dinâmica entre o mundo real e o sujeito, a qual não pode ser traduzida em números. A interpretação e a atribuição de significados são básicas na pesquisa qualitativa. A coleta 
de dados é realizada diretamente no ambiente natural, sendo o processo e seu significado, os focos principais de abordagem (SILVA; MENEZES, 2005).

De acordo com os objetivos, a pesquisa é exploratória, proporcionando conhecer melhor o contexto de trabalho do modelista de vestuário em um bureau de modelagem, com a finalidade de obter familiaridade com o problema, visando explicitá-lo e formular hipóteses. Normalmente, as pesquisas exploratórias envolvem levantamento bibliográfico, entrevistas com pessoas que atuam na área do problema pesquisado e análise de exemplos, estimulando a compreensão (GIL, 2002).

Do ponto de vista dos procedimentos técnicos a pesquisa foi desenvolvida através de um estudo de caso, permitindo o amplo conhecimento de um objeto. Nas ciências, o mesmo é classificado como mais adequado para a investigação de uma situação em seu contexto real (YIN, 2001 apud GIL, 2002).

\subsection{Etapas do estudo}

Para seguir os objetivos, o estudo foi dividido em duas etapas, sendo uma de cunho teórico que buscou levantar a base bibliográfica sobre o assunto e outra de cunho aplicado, caracterizando-se como estudo de caso em um bureau de modelagem. A figura 1 detalha as etapas deste estudo.

Figura 1 - Etapas do estudo

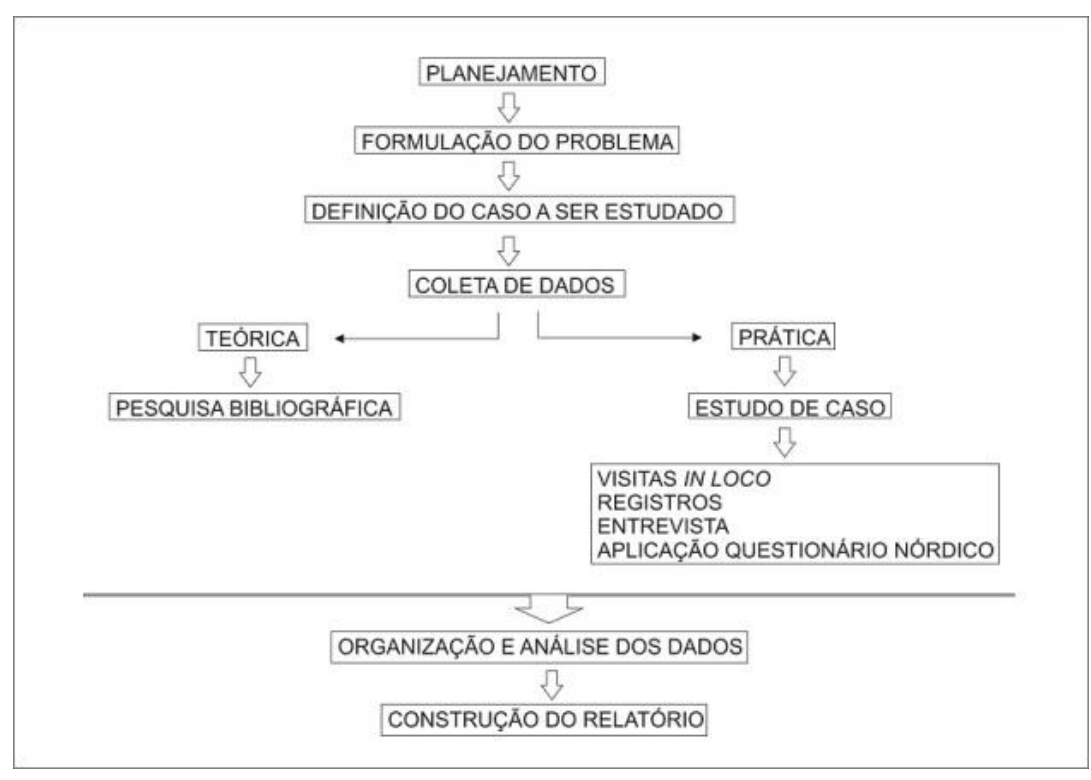

Fonte: a autora, 2015. 


\subsection{Materiais e métodos}

A pesquisa bibliográfica foi necessária para entender os conceitos relacionados ao contexto de trabalho do modelista, bem como aos conhecimentos relativos à ergonomia, em especial os aspectos físicos, os quais são objetos deste estudo. Realizada através de livros, publicações e artigos que trouxessem informações relevantes, a pesquisa bibliográfica foi necessária para entender os conceitos, bem como, buscar pesquisas já realizadas no âmbito deste assunto.

O bureau de modelagem foi visitado duas vezes, sendo que, a modelista recebeu as informações sobre a pesquisa e sua finalidade. Além disto, a mesma leu e assinou o Termo de Consentimento Livre e Esclarecido (TCLE), atestando a concordância em participar da pesquisa, respeitando assim, as normas éticas para execução da mesma.

Os dados foram coletados entre os meses de março e julho de 2015 pela própria pesquisadora, através de visitas in loco para observar o posto de trabalho e as atividades desenvolvidas, fornecendo informações na forma de registros escritos a partir de observações, bem como registros fotográficos com máquina digital. Além disto, foi realizada entrevista com a modelista, visando obter informações mais detalhadas sobre seu perfil demográfico, histórico profissional e sobre sua atividade atual. Em uma das visitas foi aplicado o Questionário Nórdico de Sintomas Osteomusculares (QNSO), objetivando conhecer os possíveis reflexos físicos causados pelo desempenho da função.

O Nordic Musculoskeletal Questionnaire (NMQ) foi desenvolvido por meio de um projeto financiado pelo Conselho de Ministros Nórdicos, tendo como objetivo padronizar a mensuração de relatos de sintomas osteomusculares, facilitando a comparação entre os estudos, com relação às regiões anatômicas e o período recordatório (KOURINKA et al., 1987 apud PINHEIRO; TRÓCCOLI; CARVALHO, 2002). O questionário também pode ser usado para apontar as condições do ambiente ou posto de trabalho (PINHEIRO; TRÓCCOLI; CARVALHO, 2002).

O Questionário Nórdico é um instrumento formado por uma figura que representa o corpo humano, dividida em regiões anatômicas, no qual o entrevistado faz as escolhas de acordo com a ocorrência de sintomas osteomusculares em períodos determinados e precedentes à entrevista, além de, indicar se houve incapacidade funcional e/ou procura por algum profissional da saúde nos últimos 12 meses. Este 
questionário foi traduzido para diversos idiomas, inclusive foi adaptado para a língua portuguesa e pré-testado, no qual os resultados ofereceram confiabilidade para usar a versão brasileira deste instrumento (BARROS; ALEXANDRE, 2003 apud CARVALHO; ALEXANDRE, 2006).

A maior dificuldade ocorreu em uma das visitas, durante a entrevista, que foi interrompida várias vezes, pois foi realizada durante o expediente e a modelista trabalha individualmente, tendo que se esforçar para realizar os atendimentos pessoais e via telefone, os quais foram vários naquela ocasião.

Os registros dos dados foram organizados e, posteriormente analisados, buscando verificar a relação entre as queixas relatadas e as atividades observadas.

\section{FUNDAMENTAÇÃO TEÓRICA}

A pesquisa bibliográfica necessária para a construção do referencial teórico foi realizada no período de março a julho de 2015. Foram consultadas in loco as bibliotecas centrais dadas universidades: Universidade Federal de Santa Catarina (UFSC), Universidade do Estado de Santa Catarina (UDESC) e Universidade Regional de Blumenau (FURB), selecionando títulos que fossem relacionados com a área de ergonomia e modelagem. Na área de ergonomia, existem vários títulos tratando a ergonomia de forma geral e sobre a ergonomia física, inclusive aplicada nas indústrias. Foram selecionadas as obras de autores renomados e que contribuíssem com o objetivo da pesquisa. Para a área de modelagem há pouca bibliografia disponível e, os livros existentes tratam, geralmente, da parte prática, mostrando como executar a modelagem através do traçado de diferentes modelos.

Foram pesquisados trabalhos na Biblioteca Digital Brasileira de Teses e Dissertações (BDTD), por abranger grande quantidade de teses e dissertações de várias instituições. Também foi realizada a pesquisa no portal de periódicos da Coordenação de Aperfeiçoamento de Pessoal de Nível Superior (CAPES). Essa base de dados foi escolhida por abranger grande número de periódicos e devido sua importância na área científica. Na pesquisa realizada nas duas bases de dados foram utilizadas as palavras chave: "modelagem vestuário", "clothing modeling" e "pattern making". Assim, foram encontrados alguns trabalhos e artigos envolvendo as áreas de modelagem e da ergonomia de forma conjunta, porém, os mesmos são focados no desenvolvimento de 
produtos do vestuário ou no ensino de modelagem, os quais não são o objeto desta pesquisa. Como resultado foi possível evidenciar que a literatura apresenta limitados estudos focando a atividade de modelista.

\subsection{Ergonomia}

A ergonomia estuda o trabalho e sua relação com o sistema-homem-máquina, buscando modificá-la, com o objetivo de proporcionar conforto, segurança e eficiência do trabalhador (IIDA, 2005). A definição de ergonomia para a IEA - International Ergonomics Association (Associação Internacional de Ergonomia):

Ergonomia (ou Fatores Humanos) é a disciplina científica que trata da compreensão das interações entre os seres humanos e outros elementos de um sistema, e a profissão que aplica teorias, princípios, dados e métodos, a projetos que visam otimizar o bem-estar humano e a performance global dos sistemas. (Ação Ergonômica: Revista Brasileira de Ergonomia, 2008, p. 3)

A partir do século XVIII, com a Revolução Industrial, o foco para as condições de trabalho nas indústrias tornou-se mais evidente, já que as mesmas possuíam péssimas condições, com jornadas diárias longas e sob regime de castigos aplicados pelos empresários da época. As primeiras pesquisas em ergonomia preocuparam-se com o trabalho em indústrias com condições extremas como mineradoras e fundições. Posteriormente, as mais importantes contribuições da ergonomia ocorreram durante as duas grandes guerras mundiais. Após a Segunda Guerra Mundial (1939-1945), as experiências e conhecimentos em ergonomia passaram a ser ainda mais aplicados à sociedade civil e às indústrias em geral, ocorrendo maior disseminação.

Nas indústrias, a ergonomia contribui para descrever e avaliar as atividades realizadas pelos trabalhadores, classificar os postos de trabalho e seus riscos ergonômicos, propondo recomendações para melhorar o nível de conforto dos mesmos através da adequação de equipamentos, layout e processos, visando transformar o trabalho e otimizar sua execução. Para isso, é importante que os equipamentos sejam projetados para o uso coletivo ao aplicar a ergonomia em postos de trabalho (DUL; WEERDMEESTER, 2004). A importância da aplicação da ergonomia em empresas está relacionada ao aumento da qualidade de vida no trabalho e motivação dos funcionários, de forma que, a execução das atividades profissionais ocorra sem afetar ou prejudicar a 
saúde do trabalhador. Busca-se através da ergonomia adaptar o trabalho ao homem, respeitando suas características, bem como, envolvê-lo nas decisões que o afetam. Conforme Dul e Weerdmeester (2004) a ergonomia possui um significado social, pois contribui para minimizar vários problemas decorrentes de situações de trabalho e do cotidiano, principalmente as doenças do sistema musculoesquelético e os problemas de ordem psicológica.

A ergonomia abrange aspectos físicos, cognitivos e organizacionais. Porém, para este estudo foram priorizados os aspectos físicos da atuação do modelista. Os aspectos físicos da ergonomia compreendem o estudo de antropometria, biomecânica, posturas, movimento e manuseio de materiais, análise dos postos de trabalho, entre outros (IIDA, 2005).

Para a atividade de modelista, uma das maiores exigências físicas é a manutenção da postura sentada por horas prolongadas, pois normalmente, realiza a modelagem de forma computadorizada, resultando em um trabalho em sua maioria, estático. O trabalho estático é caracterizado por contração prolongada da musculatura, o que implica em um trabalho de manutenção de postura, podendo provocar fadiga localizada nos músculos envolvidos. Se houver repetição prolongada da manutenção de posturas podem ocorrer dores inicialmente musculares, evoluindo para problemas nas articulações, ligamentos e tendões (KROEMER; GRANDJEAN, 2005).

Existem ainda, características do ambiente de trabalho que podem ocasionar riscos de lesões e doenças, sendo conhecidos como características ambientais (temperatura, ruído, vibração, iluminação, entre outras) e que podem ser avaliados por meio da ergonomia.

Portanto, a ergonomia possui um vasto campo de atuação e a sua principal contribuição está em melhorar a qualidade de vida dos trabalhadores através dos avanços nos projetos das máquinas, dos equipamentos, das ferramentas, do mobiliário, do posto de trabalho, do ambiente, da organização do trabalho e das relações provenientes dele.

\subsection{Indústria de confecção do vestuário}

O surgimento e a evolução da modelagem se confundem com a própria história da indumentária, pois está relacionada e é decorrente da mesma. A modelagem de 
roupas começou a ficar evidente quando gregos e romanos passaram a cortar os tecidos em forma de retângulos ou quadrados com o objetivo de dar forma às roupas. Os tecidos drapeados e modelados sobre o corpo são considerados a marca registrada do vestuário dessas antigas civilizações (DINIS; VASCONCELOS, 2014).

Após a Segunda Guerra Mundial (1939-1945), com o surgimento do prêt-àporter (do francês, pronto para vestir), a padronização dos tamanhos e a utilização de tabelas de medidas passaram a ser o ponto de partida para a modelagem e a produção de modelos em série, os quais deveriam vestir o maior número de pessoas possível. Atualmente, as indústrias ainda permanecem neste sistema de produção, da roupa padronizada e pronta para vestir.

Abaixo, apresentam-se os principais fatos que marcaram a história e o desenvolvimento da modelagem. 
Figura 2 - Modelagem através dos tempos

\begin{tabular}{|c|c|}
\hline Século XI & Tecidos e roupas vindos do Oriente. \\
\hline Periodo das Cruzadas & $\begin{array}{l}\text { Surge a técnica de corte no Ocidente e os ofícios de } \\
\text { artesãos (alfaiates, sapateiros, chapeleiros), que eram } \\
\text { contratados pelas classes nobres. }\end{array}$ \\
\hline $\begin{array}{l}\text { Seculos XV e XV } \\
\text { Renascimento }\end{array}$ & $\begin{array}{l}\text { Surgimento das fábricas de tecidos. } \\
\text { Avanços na personalização das roupas da nobreza. } \\
\text { Especialização dos Mestres Alfaiates: utilização de } \\
\text { réguas, compasso e tesoura; conhecimentos de } \\
\text { geometria, aritmética e proporção. }\end{array}$ \\
\hline 1589 & $\begin{array}{l}\text { Publicado em Madrid (Espanha), o primeiro livro sobre } \\
\text { técnicas de alfaiataria, de Juan de Alcega, intitulado } \\
\text { «Libro de geometria, practica y traçan. } \\
\text { As roupas atingiram grande elaboração e refinamento. }\end{array}$ \\
\hline 1780 & $\begin{array}{l}\text { Lançada na França, a primeira escola de moda exclusiva } \\
\text { para alfaiates e sapateiros. }\end{array}$ \\
\hline 1830 & $\begin{array}{l}\text { H. Guglielmo Compaign estabelece a primeira tabela de } \\
\text { medidas no Livro AArte da Alfaiataria, revolucionando as } \\
\text { técnicas de modelagem na Europa. }\end{array}$ \\
\hline 1847 e 1849 & $\begin{array}{l}\text { Foram inventados respectivamente a fita métrica e o } \\
\text { busto de manequim, ambos por Aléxis Lavigne. }\end{array}$ \\
\hline 1850 & $\begin{array}{l}\text { Surge na França, o conceito de Haute Couture (Alta } \\
\text { Costura), que primava pela qualidade e acabamento das } \\
\text { peças. O icone desta época foi o costureiro Charles } \\
\text { Frederick Worth que trabalhava a moulage (modelagem } \\
\text { tridimensional) e passou a produzir coleçōes } \\
\text { apresentadas em desfiles. }\end{array}$ \\
\hline 1950 & $\begin{array}{l}\text { Começaram a surgir os grandes estilistas. } \\
\text { As indústrias passaram a produzir roupas em tamanhos } \\
\text { padronizados, chamadas prêt-à-porter ou ready-to-wear } \\
\text { (pronto para vestir). } \\
\text { A técnica de modelagem mais utilizada passou a ser a } \\
\text { plana manual, realizada a partir de moldes bases e com } \\
\text { o auxilio de tabelas de medidas. } \\
\text { Surgiram revistas com tendências de moda, } \\
\text { acompanhadas de moldes prontos, acessiveis às } \\
\text { pessoas que tinham conhecimento de corte e costura. }\end{array}$ \\
\hline 1980 & $\begin{array}{l}\text { Grande crescimento da indústria de confecção e } \\
\text { surgimento dos Cursos de Moda no Brasil. } \\
\text { Ampliaçāo da implantação de sistemas informatizados } \\
\text { de modelagem, nas indústrias de confecçāo brasileiras. }\end{array}$ \\
\hline
\end{tabular}

Fonte: baseado em SOARES, 2009.

No contexto industrial brasileiro, as indústrias de confecção de vestuário representam um setor importante da economia. Conforme a Associação Brasileira da Indústria Têxtil e de Confecção - ABIT (OMC apud ABIT, 2015), em 2012, o país foi classificado como a quarta maior potência na atividade industrial de confecção de vestuário e acessórios do mundo. A indústria da moda é a segunda maior empregadora 
do país e, aproximadamente $\mathrm{R} \$ 100$ bilhões são faturados por ano, através de mais de 30 mil empresas. O estado de Santa Catarina se destaca no setor, principalmente, pela Região do Vale do Itajaí, sendo descrita como um dos polos confeccionistas mais avançados do país. Conforme dados da Federação das Indústrias do Estado de Santa Catarina FIESC (MTE apud FIESC, 2014), em 2013 o número de indústrias de confecção era de 8.302, com aproximadamente 113.489 trabalhadores. A participação do segmento de confecção catarinense sobre o mesmo setor nacional, levando em consideração o Valor da Transformação Industrial (VTI), em 2013 foi de 10,63\% em Santa Catarina e de $23,60 \%$ no país.

A seguir, o fluxo do processo produtivo de uma indústria de confecção do vestuário, sem considerar as especificidades individuais.

Figura 3 - Fluxo do processo produtivo na indústria de confecção do vestuário

\section{Planejamento do Processo Produtivo}

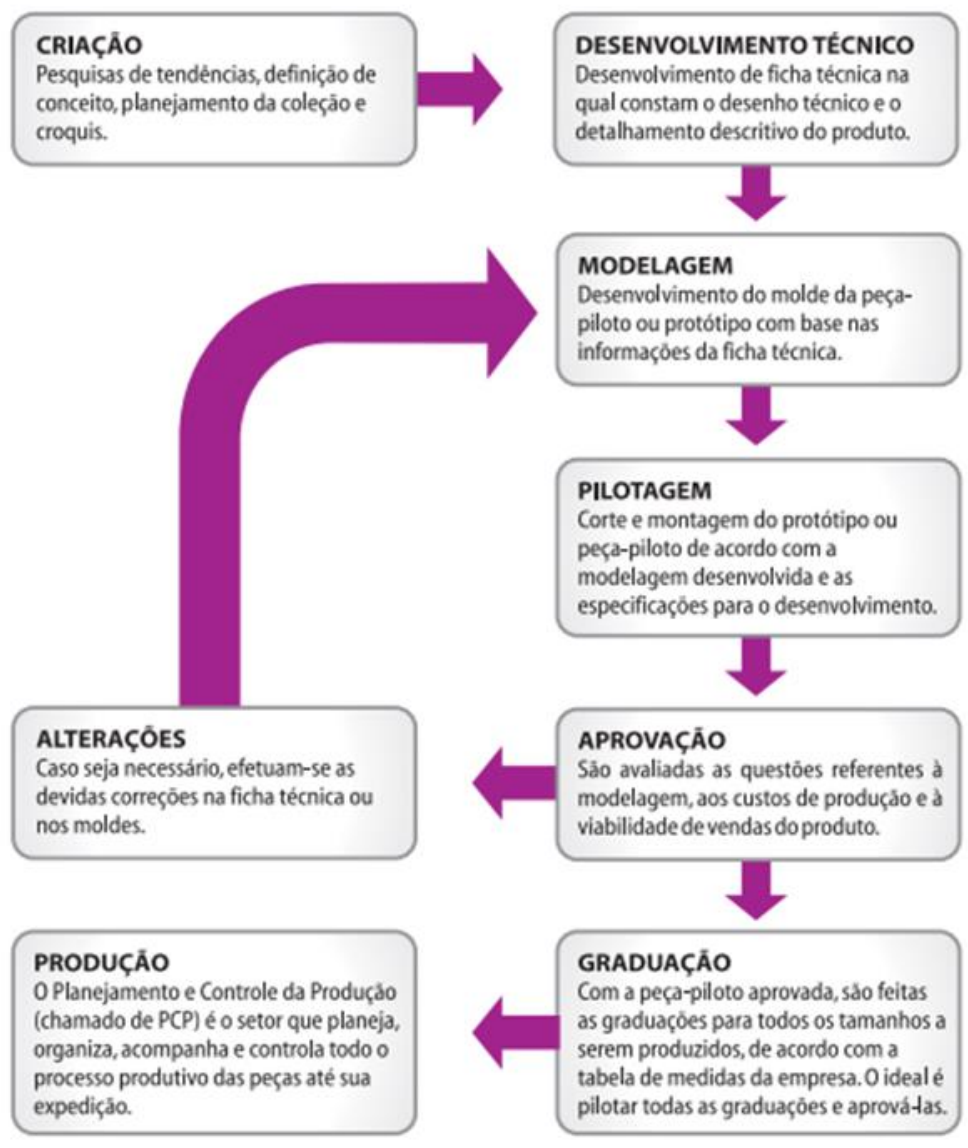

Fonte: HEINRICH, 2007, p. 10. 
O processo de uma indústria de confecção inicia com a pesquisa e criação dos modelos que farão parte da coleção. Após esta etapa, cabe ao modelista, utilizando-se de seus conhecimentos e experiência, materializar a ideia, construindo os moldes que representarão as partes componentes da peça. Quando se trata de produção em série, no caso da indústria de confecção do vestuário, os moldes são fundamentais para prosseguir e otimizar as etapas posteriores do processo.

A modelagem deve ser considerada um elemento de diferenciação, pois permite agregar às roupas aspectos como: conforto, liberdade de movimentos, segurança e satisfação do cliente, bem como, contribui para a fixação da marca. Quando a modelagem apresenta problemas faz com que as peças sejam rejeitadas pelos consumidores. Para Grave (2004, p. 11) "Um indivíduo envolvido em vestes exerce interatividade de ações e movimentos, expostos por meio de pensamentos e sentimentos, fazendo delas uma extensão do seu próprio corpo".

Assim, é importante compreender que a etapa de modelagem é estratégica para a indústria de confecção, já que, influencia no resultado final de um produto. Se um modelo apresentar um defeito, comprometerá toda a produção e impactará nos resultados da empresa. Ao mesmo tempo, os moldes devem permitir agilidade e produtividade, e a utilização correta dos tecidos, pois a modelagem sofre diversas variações dependendo do produto, medidas dos usuários, tecidos, entre outros.

\subsubsection{Modelista e sua atividade}

O profissional de modelagem, mais conhecido como modelista, atua principalmente em indústrias de confecção de peças do vestuário ou em bureaux de modelagem e desenvolvimento de produtos para confecção. De forma geral, sua atividade consiste em materializar as criações de estilistas, transformando as mesmas em moldes que irão compor o modelo, tornando possível sua produção em grande escala. Conforme a Classificação Brasileira de Ocupações (MINISTÉRIO DO TRABALHO E EMPREGO, 1997) a ocupação de Modelista de roupas ou Moldador de roupas é caracterizada pelas atividades de: confecção de moldes, pesquisa de estilo, design e tendências de mercado e avaliação de materiais para o desenvolvimento de protótipos. Para exercer a profissão é necessário curso técnico de nível médio ou experiência na função, de pelo menos dois anos. O trabalho é desenvolvido em grande 
parte individualmente, normalmente executado em horário diurno e em ambiente fechado, podendo gerar pressão e ocasionar estresse.

Através de observação e experiência profissional na área, percebe-se que as modelistas com mais tempo de experiência, normalmente são antigas costureiras que aprenderam a modelar no dia a dia e, posteriormente procuram um curso técnico para obter a certificação de seus conhecimentos. Na Região do Vale do Itajaí, em Santa Catarina, 53\% das modelistas possuem curso técnico (SILVEIRA et al, 2012).

A atividade principal do modelista é produzir os moldes e acompanhar os mesmos até a sua aprovação. Cada empresa, principalmente em função de seu porte e estrutura, possui uma forma específica de executar a modelagem e utilizará as técnicas também de forma variada. Porém, algumas etapas são fundamentais no desenvolvimento da modelagem: desenvolvimento do tamanho base; produção e aprovação da peça piloto; alterações e nova pilotagem, caso seja necessário; e gradação - ampliação e redução para os demais tamanhos da tabela (DINIS; VASCONCELOS, 2014).

Com os recentes avanços tecnológicos, a atividade de modelista sofreu alterações na sua forma de execução que, passou de predominantemente manual com a construção de diagramas em papel, até a inserção recente de softwares para construção dos mesmos diagramas, porém de forma computadorizada. Além disto, atualmente as empresas e os profissionais deste setor já possuem opções de programas para realizar a modelagem tridimensional, também de forma computadorizada, agilizando e proporcionando ainda mais confiabilidade no processo de construção de moldes.

Desta forma fica evidente a contribuição da ergonomia no setor de modelagem, o qual apresenta exigências físicas, como: postura predominantemente sentada e condicionada pelo ambiente, em especial pelo mobiliário e equipamentos informatizados; movimentos repetitivos; exigências visuais e de atenção; associadas às exigências de produção, enfatizam os riscos físicos, os quais foram evidenciados em diversos estudos (SENA et al., 2008 apud MAZINI FILHO et al., 2014), (COUTO; CARDOSO, 1995 apud MAZINI FILHO et al., 2014) e (MORAES et al., 2002 apud MAZINI FILHO et al., 2014). 


\section{ESTUDO DE CASO}

Em virtude da escassez de dados e informações sobre a atividade de modelista, optou-se por fazer um estudo de caso com uma modelista que trabalha de forma terceirizada, em um bureau de modelagem. A empresa foi escolhida por atuar há anos no mercado, atendendo diversas confecções de pequeno e médio porte.

\subsection{Visita in loco, registros e entrevista}

\subsubsection{Caracterização geral}

O bureau de modelagem pesquisado está situado na cidade de Gaspar/SC, no qual apenas a proprietária atua como modelista, sendo que oferece os serviços de: construção e alteração de modelagens (somente para modelos em malha e tecidos com elasticidade) em sistema informatizado Audaces Vestuário Moldes 11, encaixe de peças em sistema informatizado Audaces Vestuário Encaixe 11 e plottagem de riscos (impressão de encaixes). A empresa já atua no mercado há aproximadamente 7 anos. Foram realizadas duas visitas ao bureau de modelagem, sendo a primeira para esclarecer a finalidade da pesquisa e solicitar a permissão para a realização da mesma. Além disto, foi realizado o registro fotográfico do ambiente, posto de trabalho e equipamentos existentes no bureau de modelagem. Observou-se o trabalho de modelagem e foi realizada uma entrevista com o objetivo de obter informações mais detalhadas sobre seu perfil demográfico, histórico profissional e sobre sua atividade atual. A entrevista foi baseada em uma conversa na qual foram perguntados dados como: idade, escolaridade, percurso profissional, tempo de profissão, prática de atividade física, quantidade de horas trabalhadas por dia, sintomas de dores no corpo, entre outras informações. Na segunda visita, foi aplicado o Questionário Nórdico de Sintomas Osteomusculares, o qual será comentado na parte correspondente.

O modelista atende às pequenas confecções da cidade e região que, normalmente não possuem este profissional em seu quadro funcional, ou mesmo, confecções maiores que, em períodos sazonais não conseguem produzir todas as modelagens internamente, terceirizando uma parte desta atividade para suprir a demanda. Além disso, muitas confecções de pequeno porte não possuem um sistema informatizado ou mesmo equipamentos como plotters para realizar as modelagens, encaixes e riscos, e optam por terceirizar estes serviços como forma de agilizar o desenvolvimento e a produção das 
peças, sem a necessidade de investimento em softwares e equipamentos, nos primeiros anos de operação.

A empresa conta com apenas uma sala que possui duas portas e uma janela (Figura 4 e 5). A sala está localizada junto à residência da proprietária. O horário normal de atendimento do bureau é de segunda a sexta feira, das $7 \mathrm{~h}$ às 11:30h e das $13: 30 h$ às $18 \mathrm{~h}$.

Figura 4 - Planta baixa do bureau de modelagem

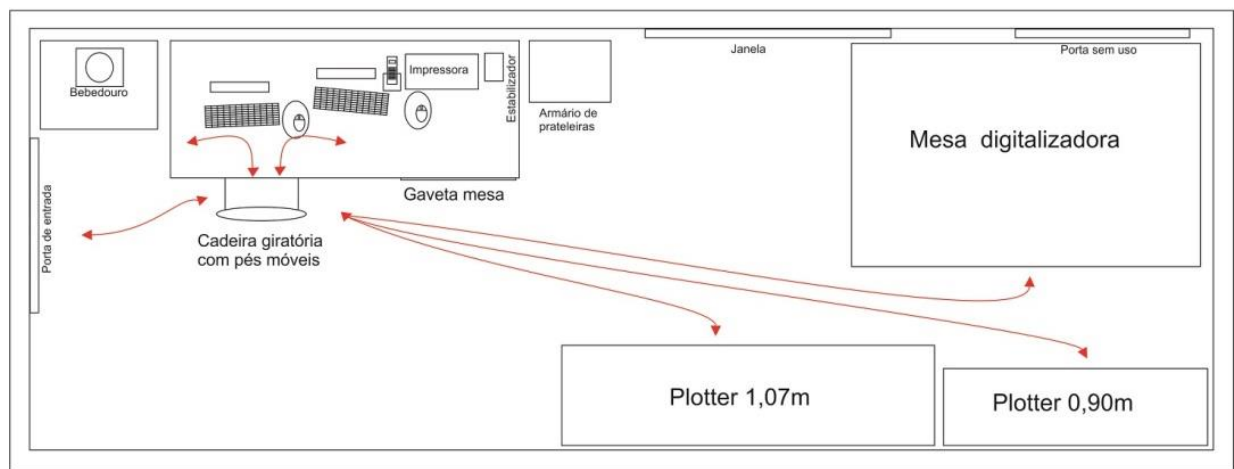

Fonte: a autora, 2015.

Figura 5 - Vista geral do bureau de modelagem

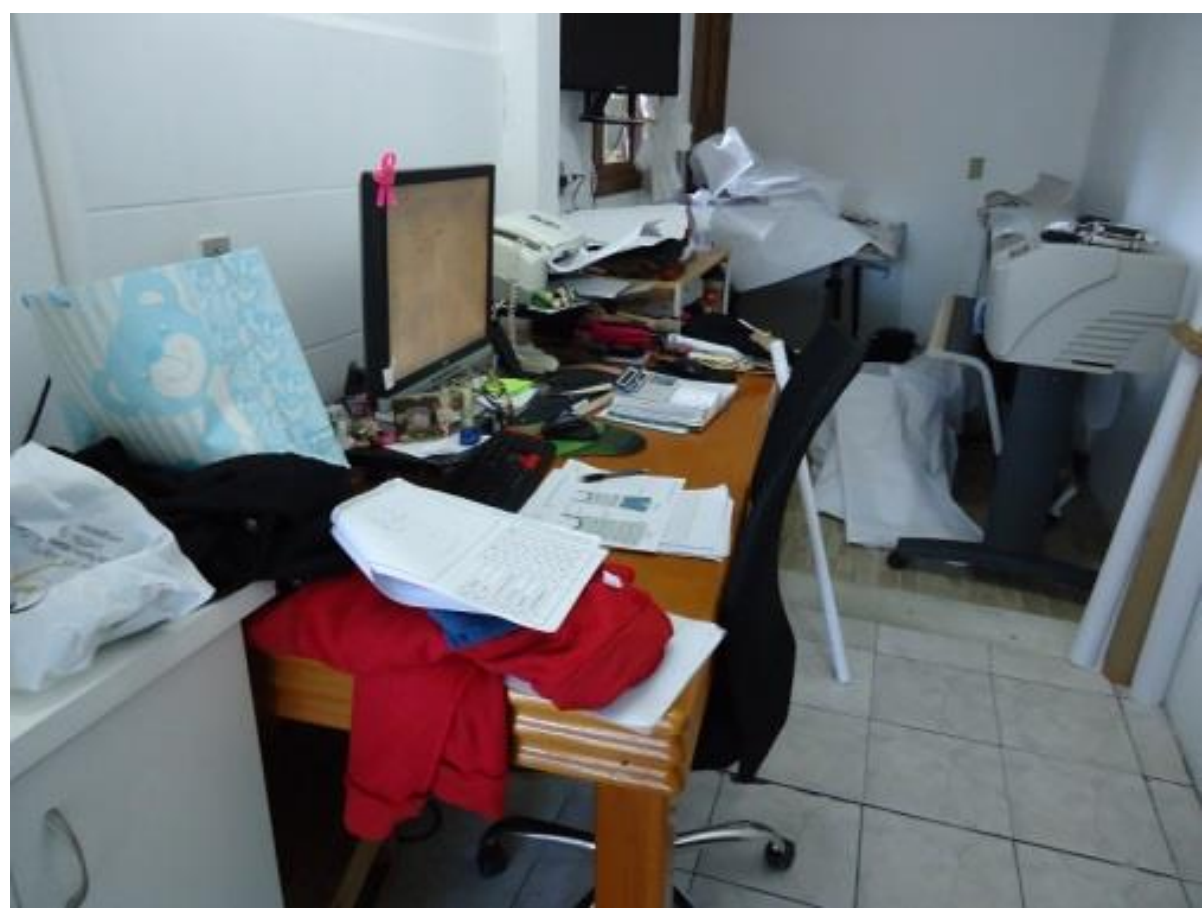

Fonte: a autora, 2015.

Os móveis presentes na sala são: uma mesa de trabalho, uma cadeira e dois armários para guardar materiais. Os equipamentos existentes são: um computador de 
mesa com o software instalado de modelagem informatizada Audaces Módulo Moldes 11 e Módulo Encaixe 11, dois monitores, dois teclados, um mouse, uma impressora comum de mesa, uma mesa digitalizadora (Figura 6), duas plotters (Figuras 7 e 8), sendo uma de largura $1,07 \mathrm{~m}$ e outra com $0,90 \mathrm{~m}$ de largura, um bebedouro e um telefone sem fio.

Figura 6 - Mesa digitalizadora no bureau de modelagem

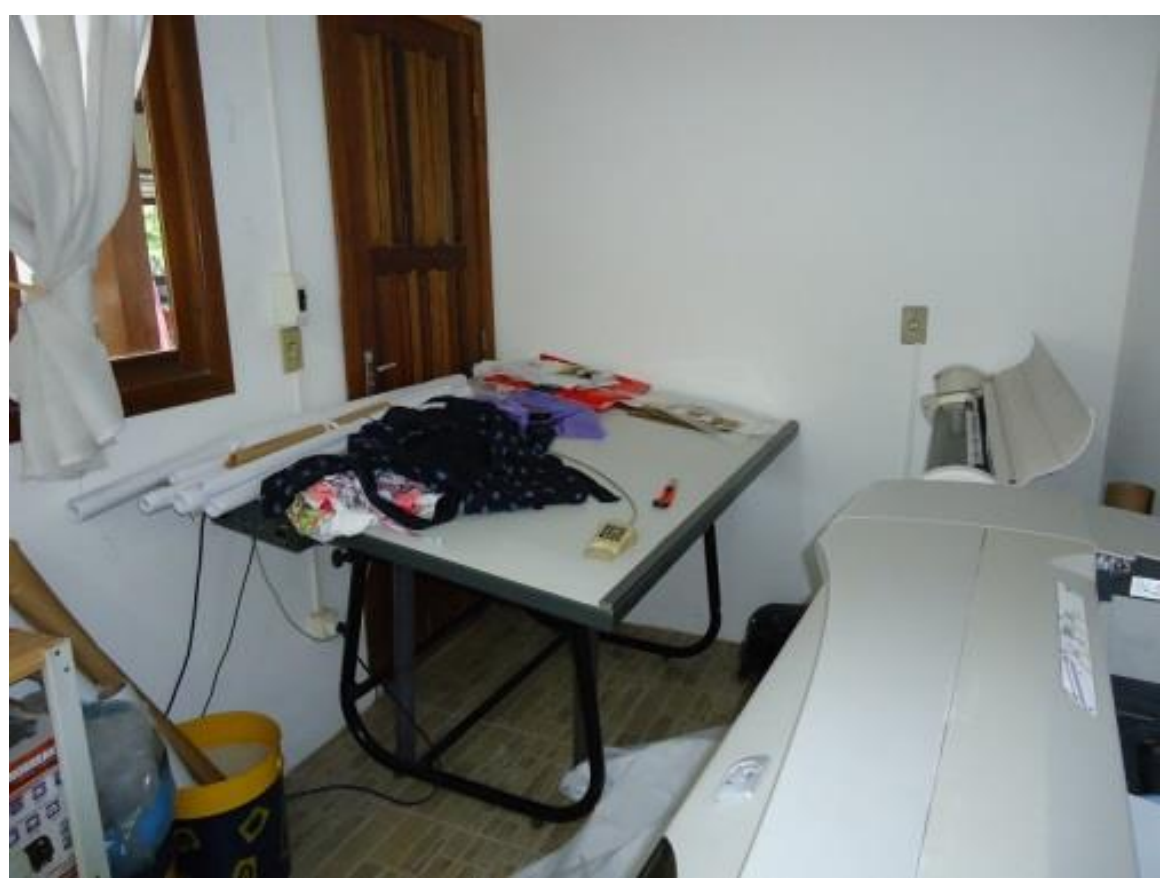

Fonte: a autora, 2015.

Figura 7 e 8 - Plotters de 1,07m e 0,90m no bureau de modelagem

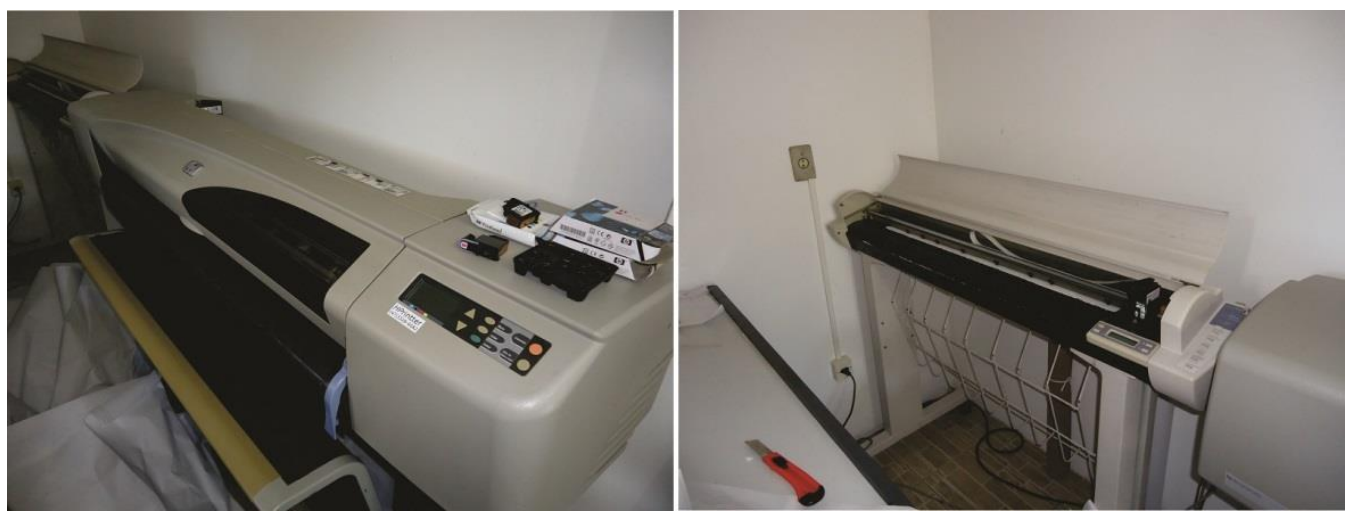

Fonte: a autora, 2015. 


\subsubsection{Caracterização do perfil da modelista}

A modelista entrevistada é do gênero feminino, tem 48 anos de idade, 1,72m de altura e pesa aproximadamente $70 \mathrm{Kg}$. Possui experiência em costura e modelagem de aproximadamente 27 anos, atuando em indústrias de confecção e em seu bureau de modelagem. Possui ensino médio completo e alguns cursos de curta duração na área de modelagem e costura, porém gostaria de fazer um curso de modelagem específico para roupas em tecido plano, pois não trabalha com esse segmento em virtude de não ter conhecimento e experiência. Antes de abrir sua própria empresa, a modelista foi sócia em outro bureau de modelagem, do qual também foi funcionária primeiramente. Anterior à esta experiência trabalhou em três indústrias de grande porte, como modelista.

A rotina atual da modelista, normalmente, inicia por volta das $5 \mathrm{~h}$ quando acorda e, muitas vezes já está trabalhando no escritório às $6 \mathrm{~h}$. No intervalo do trabalho, ela é responsável por preparar as refeições em casa, para a família. Mesmo depois do horário normal de atendimento no bureau, a modelista continua trabalhando até a noite, principalmente quando a quantidade de trabalho é muito grande, chegando a trabalhar de 15 a 18 horas por dia. A modelista não pratica atividade física regular e há alguns meses está fazendo massagem para aliviar as dores e tensão que sente nas costas, ombros e pescoço.

A entrevistada também relatou que acredita ser a utilização frequente do mouse com a mão direita, um dos fatores mais prejudiciais ao seu trabalho, ocasionando as dores nos braços, mãos e dedos. Inclusive, a mesma diz já ter tentado usar o mouse com a mão esquerda para alternar a utilização dos membros e minimizar as dores, porém, não obteve sucesso. No posto de trabalho, a modelista já trocou de mesa e de cadeira com o objetivo de realizar melhorias que proporcionem mais conforto e menos dor, porém fez isto sem nenhuma orientação ou informação prévia.

\subsubsection{Atividades da modelista}

As principais atividades desempenhadas pela modelista são: atendimento de clientes pessoalmente (com menor frequência); atendimento de clientes ao telefone e por e-mail (com maior frequência); realizar modelagem e alterações em sistema informatizado; realizar encaixe de peças em sistema informatizado, conforme grade de 
tamanhos e outras especificações enviadas pelos clientes; impressão de riscos para enfestos; enrolar o papel dos riscos, pois as duas plotters não possuem essa funcionalidade, na qual ao mesmo tempo que o risco é impresso, vai sendo enrolado em outro rolo e basta tirar o risco deste compartimento para ser entregue ao cliente.

Assim, os principais movimentos que a modelista faz durante o trabalho, são: cliques ao utilizar o mouse para executar modelagens e encaixes; rotação do tronco sentada e movimentos repetidos com membros superiores para alcançar objetos sobre a mesa que é grande; flexão do tronco em pé para alcançar os riscos de enfestos e movimentos repetidos com membros superiores para enrolar o papel dos mesmos; segurar o telefone entre a cabeça e o ombro ao mesmo tempo em que utiliza o computador; flexão do tronco sentada e da região cervical para aproximar-se da do monitor do computador, sustentação de peso na postura sentada por tempo prolongado.

No ambiente de trabalho (Figura 9), o espaço de circulação é pequeno e os móveis devem ser analisados para verificar se estão de acordo com as medidas antropométricas, para que proporcionem maior conforto durante sua utilização, causando menos danos à saúde física da modelista.

\section{Figura 9 - Estação de trabalho da modelista}

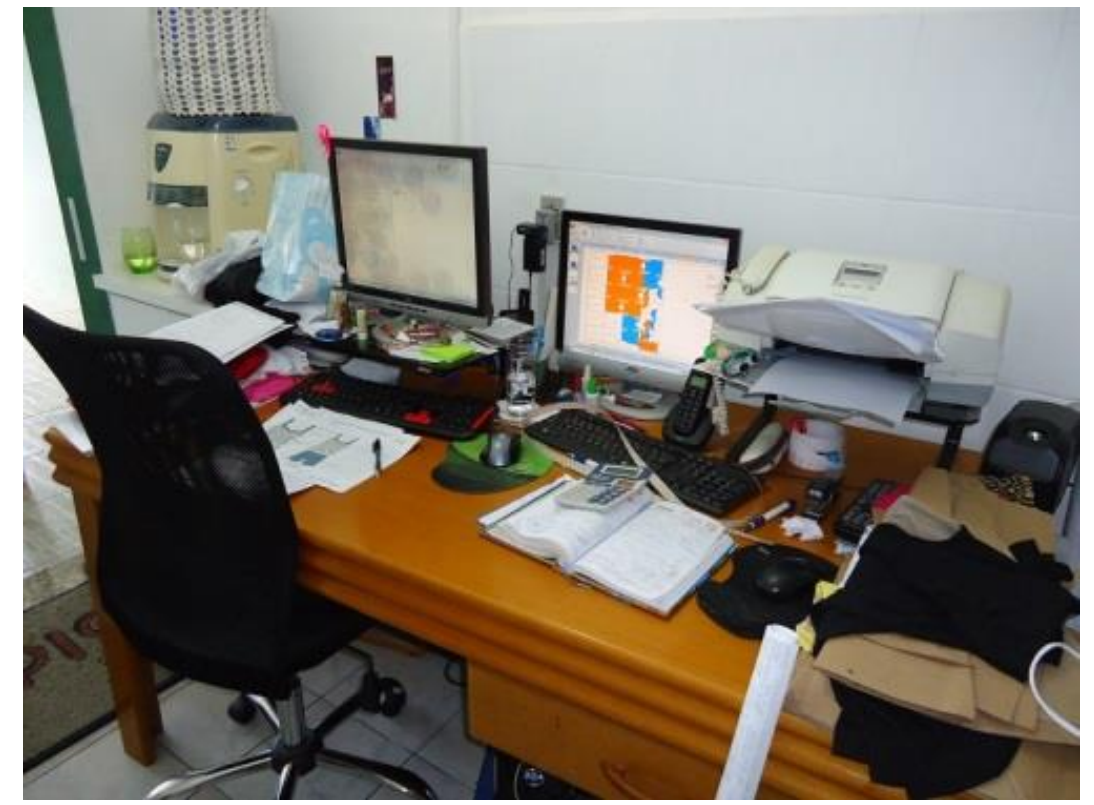

Fonte: a autora, 2015. 


\subsection{Aplicação do questionário nórdico}

Na segunda visita ao bureau foi aplicado o Questionário Nórdico de Sintomas Osteomusculares (QNSO), que identifica as partes do corpo com desconforto, causado potencialmente pelas relações com o trabalho. A versão do questionário utilizado possui uma figura humana, representando 19 regiões corporais: cabeça, olhos, ouvido, cervical, dorsal, lombar, nádegas, coxa, joelho, perna, tornozelo, pé, ombro, braço, cotovelo, antebraço, pulso, mão, e dedos. Neste questionário, o participante identifica se nos últimos 12 meses houve dor, formigamento ou dormência nas partes corporais citadas, se ocorreu algum problema nestas regiões na última semana, se esteve afastado do trabalho por algum destes problemas e, se consultou algum profissional de saúde no ano, em virtude dos problemas identificados. O questionário foi respondido pela modelista, em pausa na sua jornada de trabalho, próximo ao final da mesma e após as instruções necessárias para o correto preenchimento.

Conforme resposta ao questionário (Figura 10), a modelista no último ano apresentou: dor, formigamento ou dormência, nas regiões: cabeça; ouvido (direito); cervical; lombar; coxas (esquerda e direita); pés (esquerdo e direito); ombros (esquerdo e direito); braço (direito); pulsos (esquerdo e direito); mão (direita) e dedos (da mão direita). Na última semana, a modelista teve algum problema nas regiões: cervical; ombro (direito); pulso (direito); mão (direita) e dedos (da mão direita).

Em 2014, a modelista esteve afastada do trabalho por problemas na região lombar. Ela conta que o afastamento foi de dois dias de trabalho, após passar por consulta médica, a qual foi prescrita medicação e repouso em função de dor no nervo ciático (o qual é considerado o maior nervo do corpo humano, estendendo-se desde a coluna lombar até os pés). Ainda conforme o médico, a dor foi ocasionada por manter a postura sentada durante muito tempo, comprimindo assim o referido nervo. Na entrevista também foi relatado que durante o verão é comum a modelista ficar com os joelhos e pés inchados, porém sem dor. Ainda em 2014 a modelista consultou um oftalmologista para consulta de rotina. Há alguns meses, a modelista faz sessões de massagem relaxante com uma massoterapeuta para aliviar tensões e dores principalmente nas regiões: cervical, lombar e ombros. Ela relatou que sente dores, principalmente nos ombros, nas mãos (principalmente na direita), nos dedos, na região do pescoço e que, estas dores são mais intensas à medida que o trabalho aumenta, 
apresentando, portanto, picos sazonais. Ela acredita que as dores ficaram mais evidentes e frequentes nos últimos três anos e atribui a causa das mesmas à tensão e à pressão que o trabalho exerce.

\section{Figura 10 - Regiões corporais acometidas}

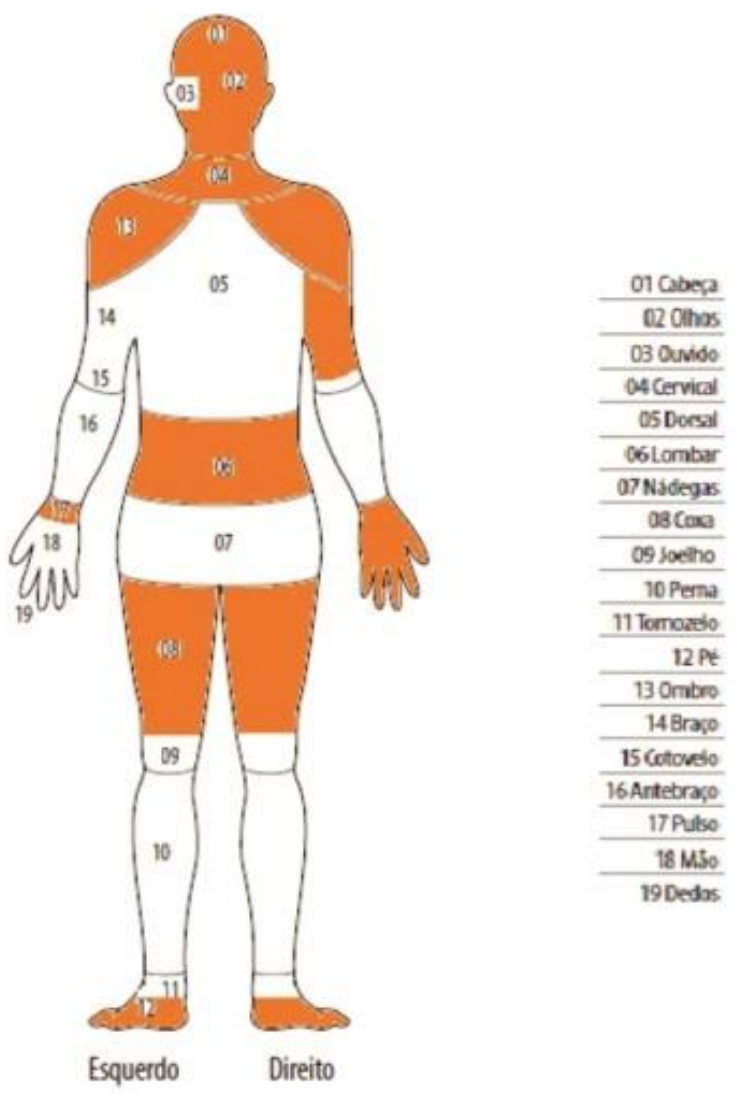

Fonte: a autora, 2015.

\subsection{Análise dos dados}

Especificamente o estudo de caso apontou problemas no ambiente de trabalho, bem como riscos físicos: mobiliário inadequado; espaço reduzido; exigências de atendimento de metas, pois se trata de uma atividade autônoma, na qual são prestados serviços para empresas com normas e procedimentos diferentes, o que acarreta maior desgaste físico e mental; manutenção da postura sentada por período prolongado e sem pausas; movimentos repetitivos; exigências visuais; reflexos diretos na saúde física com queixas de dores e desconfortos em várias partes do corpo, principalmente na região 
cervical e membros superiores, os quais se associam diretamente às posturas adotadas, exigidas pela atividade e condicionadas pelo mobiliário. Outro aspecto, que não foi foco do estudo, porém ficou evidente: a exigência cognitiva advinda da pressão do trabalho, principalmente por se tratar de serviço terceirizado, no qual a responsabilidade está centralizada em uma única pessoa.

Constata-se que há utilização de algumas posturas incorretas e que, os móveis utilizados foram comprados sem orientação e adequação às condições antropométricas da usuária. O espaço de circulação da sala também é pequeno, o que prejudica a execução de movimentos posturais corretos, principalmente na utilização da mesa digitalizadora e plotters. Estes fatores, considerados em conjunto, somados à rotina sedentária, estresse ocasionado por picos de trabalho e excesso da jornada de trabalho podem contribuir para a manutenção do quadro de dor frequente em várias regiões do corpo, bem como, em eventuais afastamentos ou incapacidade para o trabalho. A procura por auxílio de profissionais da área da saúde reforça que os sintomas osteomuculares representam um problema para o desempenho das funções da modelista.

Os dados coletados sugerem que os sintomas osteomusculares representam risco ocupacional para os modelistas. A falta de organização e ritmo do trabalho, condicionamento físico, mobiliário inadequado, repetição das atividades, cobrança por produtividade, pressão no ambiente de trabalho e sobrecarga física são alguns dos fatores que levam o profissional a desenvolver doenças ocupacionais. Os sintomas iniciam com dor e desconforto físico e, posteriormente evoluem para o formigamento e dormência de regiões corporais. Estes problemas são provocados pelo excesso de uso do sistema musculoesquelético durante as atividades profissionais. Como consequência, se não tratadas as causas do problema, a circulação sanguínea pode ficar prejudicada e ocorrerem processos inflamatórios, resultando no afastamento das atividades profissionais.

\section{CONCLUSÃO}

As exigências físicas na atividade de modelista foram o foco deste trabalho e, mesmo sendo um estudo inicial permitiu constatar que é um vasto campo a ser explorado. Assim, como muitas atividades na indústria em geral, o modelista pode estar exposto a diversos riscos do ponto de vista da ergonomia. Estes riscos não se limitam 
apenas aos físicos, mas podem abranger aspectos cognitivos e organizacionais. Na pesquisa, foram focados aspectos físicos e caracterizada a atividade do modelista e suas exigências físicas. $\mathrm{O}$ estudo ergonômico evidenciou a presença de exigências físicas, bem como problemas musculoesqueléticos decorrentes do desempenho da atividade.

O objetivo da pesquisa foi alcançado com a identificação das exigências físicas associadas a atividade de modelista do vestuário realizadas em um bureau de modelagem, o que permitiu conhecer a rotina da profissão e visualizar aspectos importantes in loco.

Os procedimentos adotados foram adequados à situação, porém não foram suficientes, já que, a atividade do modelista é bastante complexa e podem ser extraídos ainda mais dados, além de analisadas outras variáveis, contribuindo para enriquecer a pesquisa, desta atividade que carece de estudos científicos.

Este estudo permite contribuir para a qualidade de vida do profissional da área de modelagem, bem como da indústria de confecção em geral, pois muitas das funções existentes são repetitivas e executadas predominantemente na postura sentada. Estudar as causas e seus efeitos permite ampliar o escopo de visão, buscando estratégias e alternativas, visando melhorar o ambiente e a execução do trabalho. Além disto, permite chamar a atenção, ampliando o conhecimento já existente, bem como, fomentar pesquisas posteriores na área, inclusive com relação a outros aspectos da ergonomia como os cognitivos e organizacionais.

\section{Artigo recebido em Outubro de 2015. Aprovado em Maio de 2016} DOI:http://dx.doi.org/105965/1982615x09182016281

\section{REFERÊNCIAS}

ASSOCIAÇÃO BRASILEIRA DA INDÚSTRIA TÊXTIL E DE CONFECÇÃO ABIT (São Paulo) (Ed.). Agenda de Prioridades: Têxtil e Confecção - 2015/2018. São Paulo, 2015. Disponível em:

<http://www.abit.org.br/conteudo/links/publicacoes/agenda_site.pdf >. Acesso em: 25 ago. 2015. 
ASSOCIAÇÃO BRASILEIRA DE ERGONOMIA (Rio de Janeiro). O que é ergonomia. Disponível em:

<www.abergo.org.br/internas.php?pg=o_que_e_ergonomia>. Acesso em: 21 jun. 2015.

CARVALHO, AJFP; ALEXANDRE, NMC. Sintomas osteomusculares em professores do ensino fundamental. Revista Brasileira de Fisioterapia, São Paulo, v. 10, n. 1, p.35-41, 2006. Disponível em: < http://www.scielo.br/pdf/rbfis/v10n1/v10n1a05.pdf>. Acesso em: 30 ago. 2015.

DAIANE PLETSCH HEINRICH (Rio Grande do Sul). Sebrae. Modelagem: ferramenta competitiva para a indústria da moda. Porto Alegre: Feevale, 2007. Disponível em: <http://201.2.114.147/bds/bds.nsf/9AFBA8F1EE63475983257457004FA761/\$File/NT 0003798A.pdf >. Acesso em: 07 maio 2015.

DINIS, Patrícia Martins; VASCONCELOS, Amanda Fernandes Cardoso. Modelagem. In: SABRÁ, Flávio (Org.). Modelagem: tecnologia em produção do vestuário. 2. ed. São Paulo: Estação das Letras e Cores, 2014. Cap. 3. p. 54-125. Rev. e aum..

DUL, Jan; WEERDMEESTER, Bernard. Ergonomia prática. 2. ed. São Paulo: Edgard Blücher, 2004. Tradução: Itiro lida. Rev. e ampl..

FEDERAÇÃO DAS INDÚSTRIAS DO ESTADO DE SANTA CATARINA - FIESC (Santa Catarina). Unidade de Política Econômica e Industrial. Santa Catarina em Dados: 2014. v.24. Florianópolis: Fiesc, 2014. Disponível em: <http://fiesc.com.br/sites/default/files/medias/25_set_sc_dados_2014_em_baixa_para_s ite.pdf>. Acesso em: 30 ago. 2015.

GIL, Antônio Carlos. Como elaborar projetos de pesquisa. 4. ed. São Paulo: Atlas, 2002.

GRAVE, Maria de Fátima. A modelagem sob a ótica da ergonomia. São Paulo: Zennex Publishing, 2004.

KROEMER, K.H.E.; GRANDJEAN, E.. O trabalho muscular. In: KROEMER, K.H.E.; GRANDJEAN, E.. Manual de ergonomia: adaptando o trabalho ao homem. 5. ed. Porto Alegre: Bookman, 2005. Cap. 1. p. 11-22.

IIDA, Itiro. Ergonomia: projeto e produção. 2. ed. São Paulo: Blucher, 2005. Rev. e ampl.

INTERNATIONAL ERGONOMICS ASSOCIATION (USA). Conselho Científico Internacional. Definição internacional de ergonomia. Ação Ergonômica: Revista Brasileira de Ergonomia, São Paulo: Abergo, v. 3, n. 2, p. 3, 2008. Disponível em: <http://www.abergo.org.br/revista/index.php/ae/article/view/61/58>. Acesso em: 30 abr. 2015 . 
MAZINI FILHO, Mauro Lúcio et al. A visão de costureiras em relação a seus postos de trabalhos e os problemas relacionados ao mesmo. Ação Ergonômica: Revista

Brasileira de Ergonomia, Rio de Janeiro, v. 9, n. 2, p.47-66, 2014. Disponível em: <http://www.abergo.org.br/revista/index.php/ae/article/viewFile/231/215>. Acesso em: 24 mar. 2015.

MTE - Ministério do Trabalho e Emprego. Classificação Brasileira de Ocupações. Brasília: Ministério do Trabalho e Emprego, 1997. Disponível em:

<http://www.mtecbo.gov.br/cbosite/pages/home.jsf;jsessionid=wh88CkU9s25BGOGZ9 aMWfAcK.slave12:mte-229->. Acesso em: 08 mai. 2015.

PINHEIRO, Fernanda Amaral; TRÓCCOLI, Bartholomeu Torres; CARVALHO, Cláudio Viveiros de. Validação do Questionário Nórdico de Sintomas Osteomusculares como medida de morbidade. Revista de Saúde Pública, São Paulo, v. 36, n. 3, p.307312, jun. 2002. Disponível em: <http://www.scielosp.org/scielo.php?pid=S003489102002000300008\&script=sci_arttext>. Acesso em: 30 ago. 2015.

SILVA, Edna Lúcia da; MENEZES, Estera Muszkat. Metodologia da pesquisa e elaboração de dissertação. 4. ed. Florianópolis: UFSC, 2005. Rev. e atual.. Disponível em:

$<$ https://projetos.inf.ufsc.br/arquivos/Metodologia_de_pesquisa_e_elaboracao_de_teses _e_dissertacoes_4ed.pdf>. Acesso em: 25 ago. 2015.

SILVEIRA, Icléia et al. A formação dos profissionais do setor de modelagem do vestuário da Região do Vale do Itajaí-SC. DAPesquisa, Florianópolis, v. 9, n. 9, p. 552-556, ago/2011 a jul/2012. Disponível em:

< http://www.ceart.udesc.br/dapesquisa/edicoes_anteriores/9/moda/index.html> Acesso em: 21 jun. 2015

SOARES, Vera Lúcia Lins. Evolução da modelagem no design do vestuário: do simples "Ritual Ancestral" às "Técnicas". In: ENCUENTRO LATINOAMERICANO DE DISEÑO "DISEÑO EN PALERMO", 4., 2009, Buenos Aires. Actas de Diseño. Buenos Aires: Universidad de Palermo, 2009. v. 7, p. 241 - 243. Disponível em: <http://fido.palermo.edu/servicios_dyc/publicacionesdc/vista/detalle_articulo.php?id_ar ticulo=5906\&id_libro=16>. Acesso em: 24 jun. 2015. 